\title{
RECTAL LYMPHOGRANULOMA VENEREUM
}

\author{
By R. P. M. Miles, M.B., B.S., F.R.C.S. \\ Consultant Surgeon, Chichester; late Lecturer in Surgery, University College of the West Indies
}

Lymphogranuloma venereum is a disease of world-wide distribution, particularly among coloured peoples. It is prevalent in Europe, but few cases have been reported in England, 363 new cases being reported between $195 \mathrm{I}$ and 1955 (Galbraith, Graham-Stewart and Nicol, I957). It is very likely, however, that the incidence will increase with the continuation of West Indian immigration into this country.

Various other synonyms are in use for this disease-some picturesque, others frankly misleading. 'Climatic bubo' and 'Esthiomene' (from the Greek, meaning ' eating ') describe only individual aspects of the disease. "NicholasFavre' disease commemorates its French discoverers. It should not be confused with Granuloma Inguinale (or Donovanosis), an ulcerating granuloma of the skin caused by the specific Donovan body.

The disease is caused by a virus of the lymphogranuloma-psittacosis group, and there are three clinical varieties:-

I. The Inguinal (Climatic Bubo). This is an acute febrile disease affecting almost exclusively males, although purulent proctitis has been reported in males with the acute disease (Galbraith, Graham-Stewart and Nicol, 1957).

2. The Genito-Ano-Rectal Syndrome (Esthiomene). There is oedema, ulceration, and destruction of the external genitals, with urinary and faecal fistula formation. There is gross perineal scarring, with variable spread of the disease up into the rectum.

3. The Ano-Rectal Variety (which is the main subject of this paper). This occurs predominantly in women, and produces extensive lesions in the pelvic colon, rectum, and anus. It may be combined with the full genito-ano-rectal syndrome, but more commonly occurs as a lesion confined to the bowels and perineum.

It should be stressed that this disease is not confined to the rectum, but is a procto-colitis affecting the left colon in a large number of cases. It is generally conceded now that it is the commonest, if not the only, cause of inflammatory stricture of the rectum. The aetiology is not clearly understood, but it is reasonable to suppose that the rectal lesion is caused by direct invasion of the mucous membrane by the virus implanted in the anal canal through 'spill' during intercourse, although a more widely accepted theory in the past has been that of the French workers Bensaude and Lambling (1936), who stated that in the female the infection entered through a primary sore deep in the vagina, and spread via the lymphatics to the perirectal tissues; causing stricturing of the rectum from without: in the male direct implantation in the rectum took place through the practice of sodomy. In support of this they quote their findings that in women stricture is the predominant lesion, in men proco titis alone. These views are discussed and criticized elsewhere (Miles, I957). The incubos. tion period is unknown, but a long interval possibly measured in years-may intervene between exposure to infection and the onset of rectal symptoms.

\section{Clinical Manifestations}

Females are predominantly affected. In 91 윽 cases studied recently in the West Indies only six were males. The average age of patients in this series was 40 . The ano-rectal variety is seen in three phases, which overlap considerably:-

Phase I: Proctitis.

Phase 2: 'Prestricture.'

Phase 3: Established stricture.

The symptoms vary with the phase, but, in general, the first complaint is of the passage of $\frac{\text { }}{2}$ copious pus, mixed with blood, per rectum. $D$ There may be spurious diarrhoea or the passage of narrow pencil-like stools. Cramp-like abdominal No pain may be present with distension suggestive of chronic obstruction, and occasionally acute ob- $\mathcal{N}$ struction is the presenting symptom. These $\underset{\omega}{N}$ symptoms are often tolerated for months or years, and by the time advice is sought the patients areo anaemic, debilitated, and often showing toxic $\mathbb{\complement}$ manifestations of the disease, such as skin ulcera- + tion, iritis, and toxic arthritis of medium-sized $\frac{T}{T}$ joints. They may present with fistula-in-ano, $\frac{\mathrm{D}}{\mathbb{D}}$ ischio-rectal abscess, or recto-vaginal fistula. 


\section{The Rectal Lesions}

The perineum may show multiple sinuses draining pus, with large condylomatous lesions surrounding the anal orifice. A recto-vaginal fistula may be present, situated characteristically low down at the ano-rectal ring. There may be merely button-holing of the skin or complete absence of the recto-vaginal septum. However, there may be no external lesion at all, proctitis being the commonest mode of presentation. On rectal examination the granular proctitis has a typical feel resembling morocco leather. Larger polypoid granulations can often be felt, and the wall of the rectum is thickened and inelastic, so that the finger appears to be gripped by it. On withdrawal of the finger a large amount of pus pours forth. The rectal surface has a velvety appearance, bright red, with darker areas of punctate haemorrhages. Small shallow ulcers are seen. In most cases the severe infection is limited to the anus and rectum, but it is not uncommon to find the lesions extending above the full length of the sigmoidoscope.

In the prestricture phase the inflammatory changes may be much less pronounced, but fibrosis has already occurred in the rectal wall. There is a definite feeling of gripping of the finger, and the granularity of the surface has become firmer and mammilated.

The established rectal stricture is situated at two distinct levels $-2 \mathrm{~cm}$. from the anal margin (the length of the distal phalanx of the index finger) and 5 to $7 \mathrm{~cm}$. from it (the length of the distal and middle phalanges). It may vary in calibre from a slight narrowing of the rectal wall to complete stenosis. In the recent case it has a soft consistency and is easily split by the examining finger, often with considerable haemorrhage. In the long-standing case the tissues have a leathery consistency which completely bars further entry of the finger. The stricture varies in length and shape and it is convenient to describe them as being diaphragmatic, tubular or conical, although some combination of these is the most usual finding. The upward extension of the stricture cannot always be appreciated by the finger, many extending well above the rectum itself.

Radiology has revealed much information about the distribution of the lymphogranulomatous lesion in the bowel, Barium enema studies were performed on most of the cases of the series mentioned above, and, in addition to helping to define the shape of the stricture and its upward extent, it was also possible to study the spread of the disease to the rest of the left colon. The pelvic colon was commonly involved, showing narrowing and a shortening of its total length (Fig. I).

The colon proximal to this showed varying

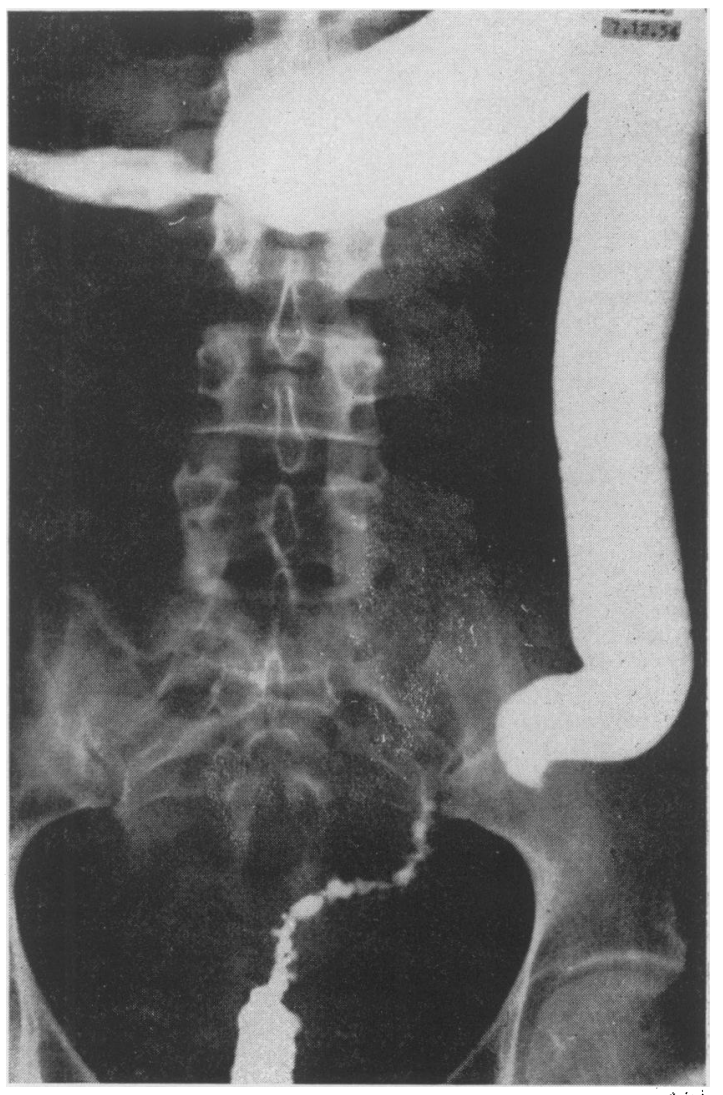

FIG. 1.-Extreme narrowing of pelvic colon and rectum, Pericolic sinuses. Tubular colon proximal to strictured area.

degrees of involvement, a ' saw tooth' pattern such as that seen in ulcerative colitis being common throughout the left colon. In some the colon has lost its haustrations and become tubular. Isolated 'skip' areas giving a 'string sign' as in regional enteritis were a striking finding (Fig. 2). Pericolic sinus formation is common, but there is no tendency to form internal fistulae.

The diagnosis is confirmed by the use of the Frei intradermal test, which is highly specific but needs experience in interpreting it, or by the lymphogranuloma complement fixation test, which has the advantage of being quantitative, being more simply performed, and requiring only one attendance by the patient.

\section{Treatment}

In the acute disease the antibiotics have proved themselves virucidal, and it is probable that the disease can be eradicated if early treatment is made available. In the chronic types, however, their effect is much less dramatic. In proctitis : ex- 


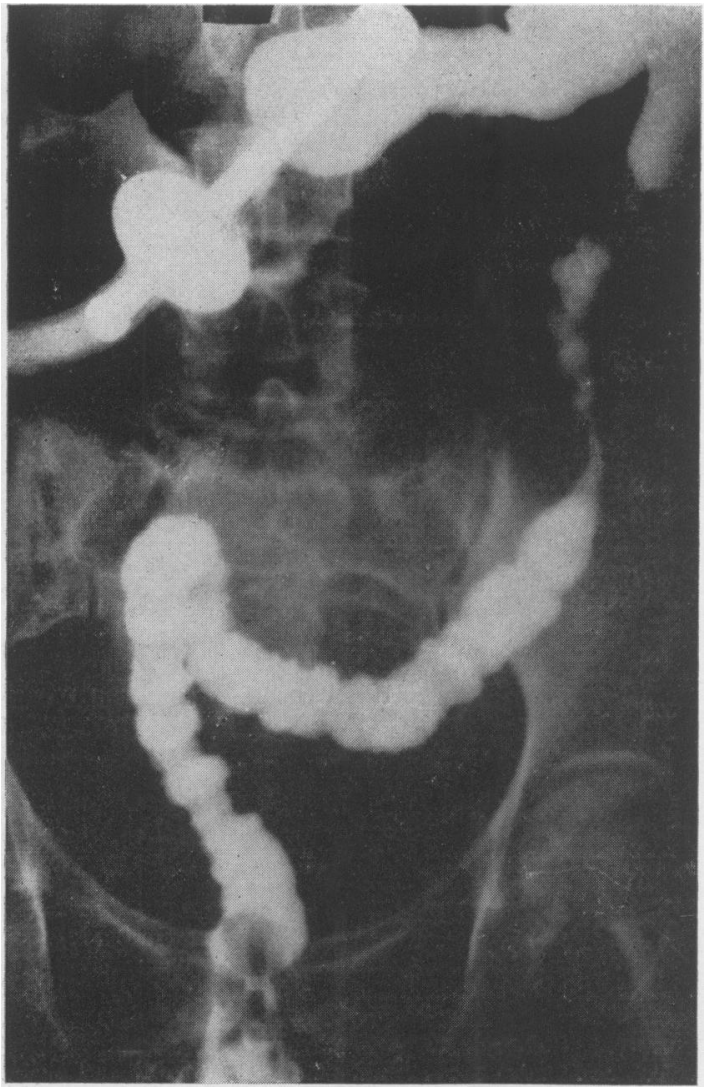

FIG. 2.-Stricturing of left colon. Extreme narrowing with a 'string sign' in descending colon.

cellent results are obtained with antibiotics, and a clinical cure can be anticipated in 80 per cent. of cases. The symptoms and signs are completely relieved, but the blood remains sero-positive for an indefinite period. Within a few days of the commencement of treatment the pain and tenesmus cease and the discharge of pus and blood is much less. Full dosage is required-28 grammes during a 14 -day course of treatment, and with this dosage the three antibiotics used-chloramphenicol, tetracycline, and erythromycin-gave equally good results.

In the established case of stricture the effect of the antibiotics must be mainly on the secondary infection, and probably as good an effect is produced by the use of the unabsorbable sulphonamides. There can be obviously no direct effect on the thick fibrous tissue of the stricture, but the resolution of the inflammatory oedema produces apparent widening of the bowel lumen, with considerable relief of symptoms. Many other types of treatment have been tried for the established stricture, most of them being in vogue before the气 aetiology of the disease was known. These 3 included rapid and intermittent dilatation, short- $\stackrel{\varnothing}{\circ}$ wave therapy, diathermy and electro-coagulation, $\subseteq$ and internal proctotomy. Radical surgery for the $\overrightarrow{\vec{F}}$ condition was first practised by Henri Hartmann? (1930), who described his operation of intra- $\frac{C}{0}$ sphincteric amputation of the rectum performed $\bar{\omega}$. on 47 cases of inflammatory stricture of the rectum. $\overrightarrow{\mathbb{D}}$ It is interesting that no mention is made in his paper of the possible aetiology of the disease.

\section{Surgical Treatment}

Many cases can be kept comfortable by courses $\vec{N}$ of antibiotics and occasional dilatation, and willo not require surgery, but the disease in the chronic $\frac{0}{3}$ cases remains active and progressive. More bowel is involved, toxic symptoms persist and the patients remain chronically anaemic and under- $\overrightarrow{0}$ weight. Malignant change to epidermoid and, occasionally, to adeno-carcinoma has been de- $N$ scribed in long-standing cases.

\section{Dilatation}

This is the most enduring of palliative methods, $\frac{\mathbb{D}}{\mathrm{C}}$ but care must be exercised in its use. Too forceful dilatation causes sudden splitting of the strictured area, with haemorrhage and perforation of tec rectal wall. Very considerable fibrosis occuas. during healing, and the lumen of the stricture 90 thereby diminished. In this connection mention might be made of the 'fibro-plastic diathesis' of $\bar{\partial}$ the Negro (Matas, I896; Rosser, 1923), whereby all fibrous tissue growth is greatly exaggerated, $\stackrel{\mathbb{Q}}{\stackrel{2}{\circ}}$ e.g., in healing wounds, keloids, fibromata, and $\overrightarrow{\vec{F}}$ strictures. It certainly makes all attempts at $\frac{3}{3}$ intermittent dilatation of strictures very uncertain of success.

\section{Colostomy}

This may be indicated in cases with obstruction, whether further surgery is planned or not. Where major surgery is planned a preliminary colostomyo is nearly always indicated. Permanent colostomy, however, should be avoided as many of these? patients are comparatively young women, and the $>$ disease, if left in situ, may progress upward to in-을. volve the colostomy stoma. A transverse colos- $\bar{N}$ tomy is advisable to avoid this possibility and also. to allow adequate room for mobilizing bowel at $N$ any subsequent operation.

\section{Radical Surgery}

Removal of the diseased rectum and colon has $\frac{0}{\Phi}$ been practised in many clinics dealing with large $\stackrel{?}{+}$ numbers of coloured patients. Bacon (194I) advocated a two-stage perineal resection with permanent colostomy. Woods and Hanlon (1944) $\stackrel{\mathbb{P}}{\stackrel{\mathbb{P}}{\circ}}$ 
performed 35 recto-sigmoid resections with good results (and incidentally comment on the poor results obtained in treating 108 cases by dilatation only). Wright, Berg, Bolden and Freeman (1946) describe 26 cases treated by intra-sphincteric resection following the technique of Pauchet and Hartmann. Breidenbach and Slattery (r948) described 18 cases treated by sacro-perineal excision and reanastomosis of bowel to anus.

The ideal type of operation is a restorative resection with the colon sutured to the anal stump. However, most of the strictures are at too low a level for this operation to be feasible, and in the author's experience the most generally useful is the abdomino-anal pull through operation (Pauchet and Hartmann), in spite of the fact that rectal sensation is lost or severely impaired, and control is not always perfect. The abdomen is explored first to ascertain the extent of the disease. Where skip areas of disease are present these may have to be resected and end-to-end anastomosis performed. The bowel is mobilized to its fullest extent to ensure adequate length to reach the anus. The perineal part of the operation consists in removal of the rectum after careful dissection of the sphincters. The preservation of the muscle ring is extremely important, and if this proves impossible, owing to involvement by disease, the operation is best abandoned.

In cases with advanced disease, with extensive fistula formation and complete destruction of the rectal wall, an abdomino-perineal resection with permanent colostomy is performed.

\section{Pathological Features}

The naked eye appearance of the diseased bowel is shown in Fig. 3-a specimen removed by abdomino-perineal resection. The rectal surface is denuded of epithelium and is covered with haemorrhages. The strictured area extends into the distal part of the pelvic colon, and the cut surface shows the considerable thickening of the wall, this being most pronounced in the submucosa. Also shown in this specimen is a rectovaginal fistula and extensive condylomata formation. Histologically, there is a non-specific inflammatory reaction extending through all layers, but more pronounced near the inner coats. The mucosa is practically absent, being replaced by granulation tissue, and the submucosa shows very considerable thickening, with much fibrous tissue, obliterative endarteritis and aggregations of lymphocytes.

\section{Discussion}

More study is required before the real mode of formation of the striking bowel lesions found in

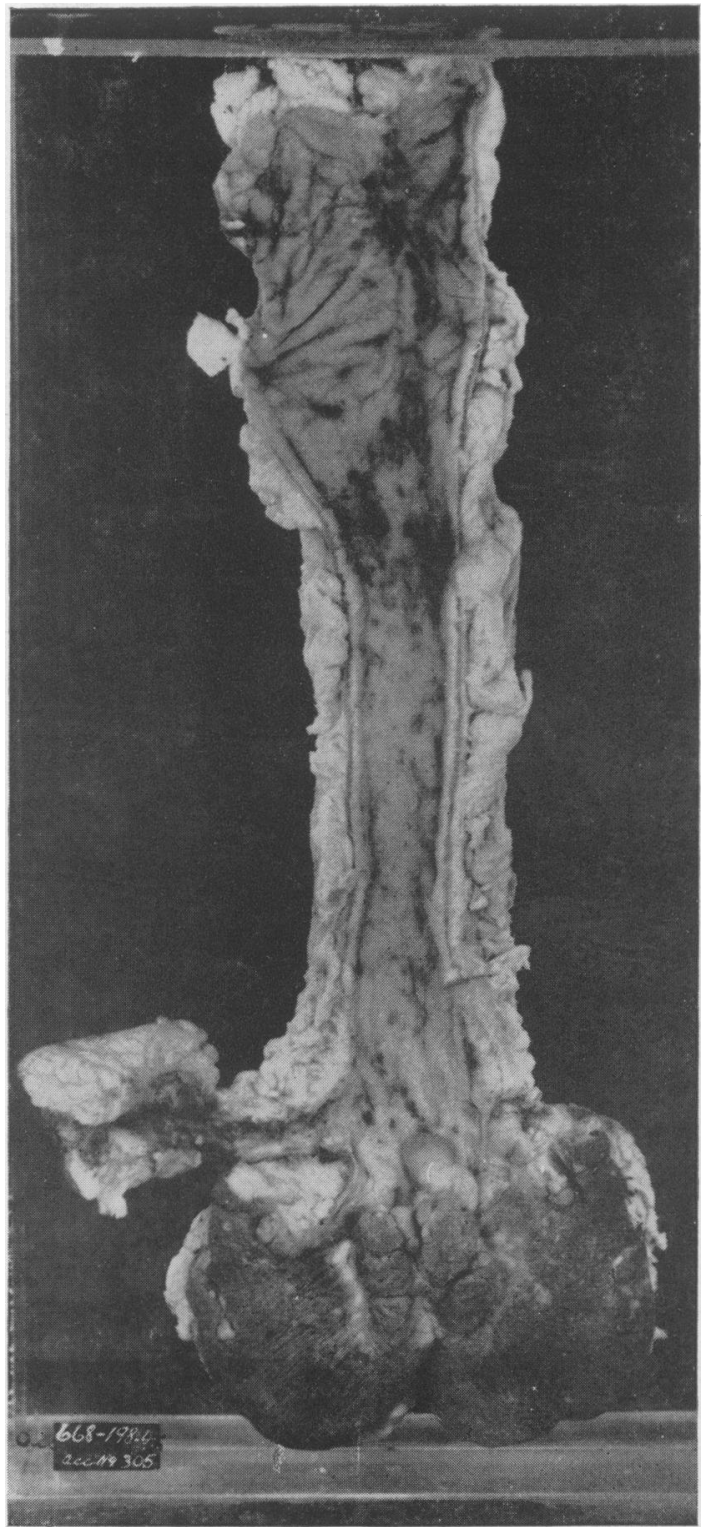

Fig. 3.- Specimen removed by abdomino-perineal resection.

lymphogranuloma venereum is known. It is by no means clear how the lesions actually commence, but it would not seem to be as a direct result of the virus. It is more reasonable to suppose that the lesions represent the reaction of the bowel to certain stimuli, e.g., an allergic or anaphylactic phenomenon. The general naked eye, pathological, and radiological appearances have many features common to the other granulomatous affections of the bowel, conditions to which we 
are forced to give names which mask our ignorance of their true nature-regional enteritis and colitis, ulcerative colitis, hyperplastic tuberculosis (Lumb, 195I). (It must be admitted that the latter may be occasionally a genuine entity.) In bacillary and amoebic dysentery a very similar non-specific bowel lesion is found. It is reasonable to suppose that the bowel reacts in a general non-specific manner to the various toxins or antigenic substances produced in a group of conditions, some without any specific aetiological agent, others with such an agent, one of which is the virus of lymphogranuloma venereum.

\section{Summary}

I. Lymphogranuloma venereum is a disease of world-wide distribution.

2. The ano-rectal variety of the disease produces extensive bowel lesions and is the main cause of inflammatory stricture of the rectum.

3. The treatment of these is by means of anti- biotics in the milder, earlier lesions, and by surgery $\frac{2}{3}$ in the later, severe cases of stricturing.

4. The disease bears many similarities to the $\frac{\Omega}{c}$ other non-specific granulomata that affect the large bowel.

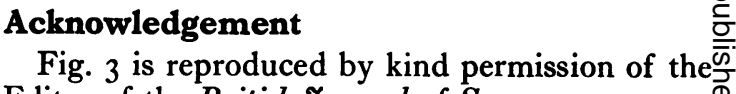
Editor of the British Fournal of Surgery.

\section{BIBLIOGRAPHY}

BACON, H. E. (1941), Sth. med. F. (Nashville), 34, 31. $\vec{\circ}$ BENSAUDE, R., and LAMBLING, A. (1936), Proc. roy. Soc. Med.,

BREIDENBACH, L., and SLATTERY, L. R. (1948), Ann. Surg., 128, 1079.

GALBRAITH, H. J. B., GRAHAM-STEWART, C. W., NICOL,

C. S. (1957), Brit. med. F., il, 1402.

HARTMANN, H. (1930), Bull. Soc. nat. Chir., 56, 855.

LUMB, G. (1951), Brit. $\mathcal{F}$. Surg., 39, 233.

MATAS, R. (1896), Trans. Amer. surg. Ass., 14.

MILES, R. P. M. (1957), Brit. F. Surg., 45, 180.

ROSSER, C. (1923), Amer. F. Surg., 37, 265.

WOODS, F. M., and HANLON, C. R. (1944), Ann. Surg., 120, 598. iv WRIGHT, L. T., BERG, B. N., BOLDEN, J. V., and FREEMAN,음

W. A. (1946), Surg. Gynec. Obstet., 82, 449.

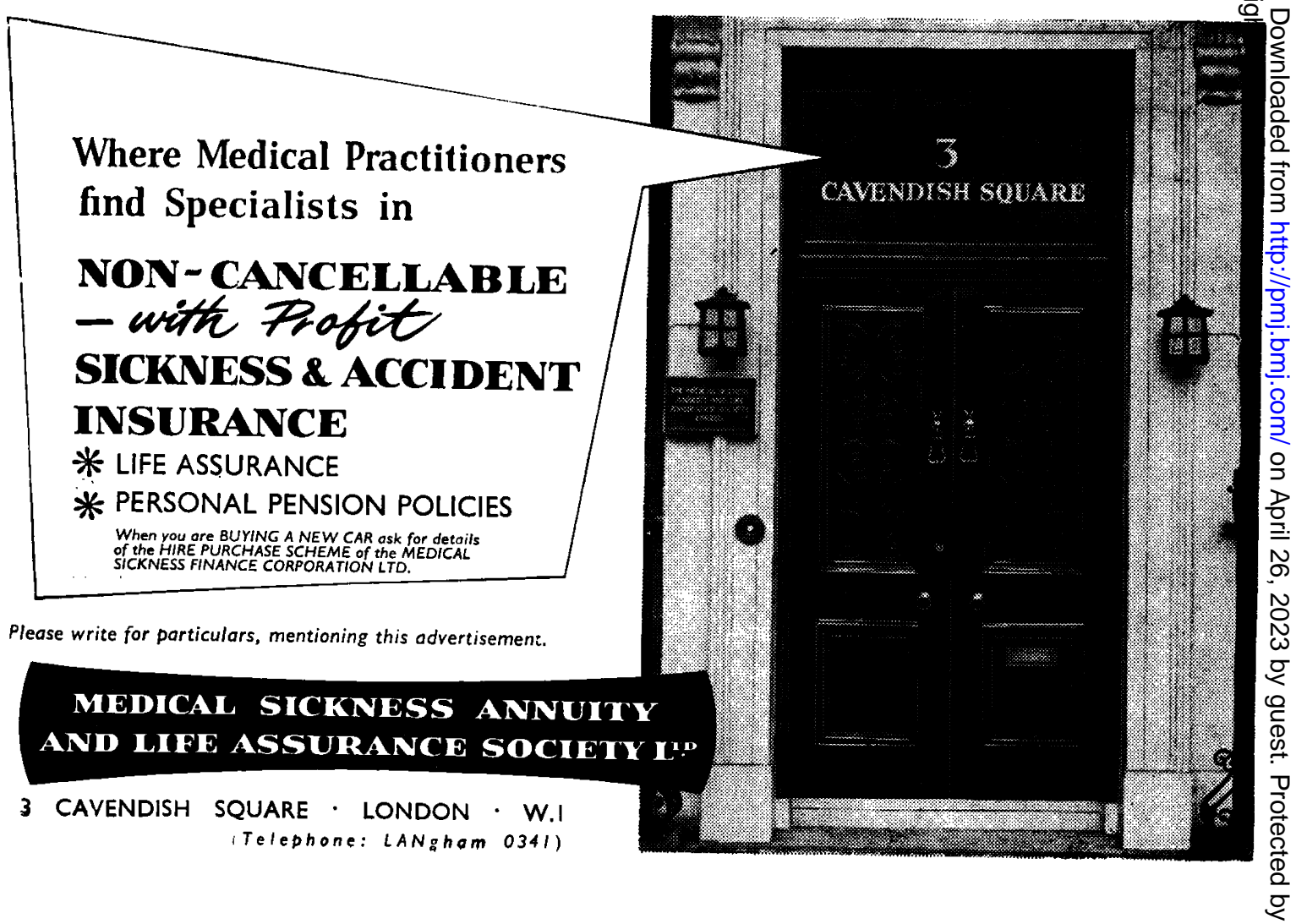

